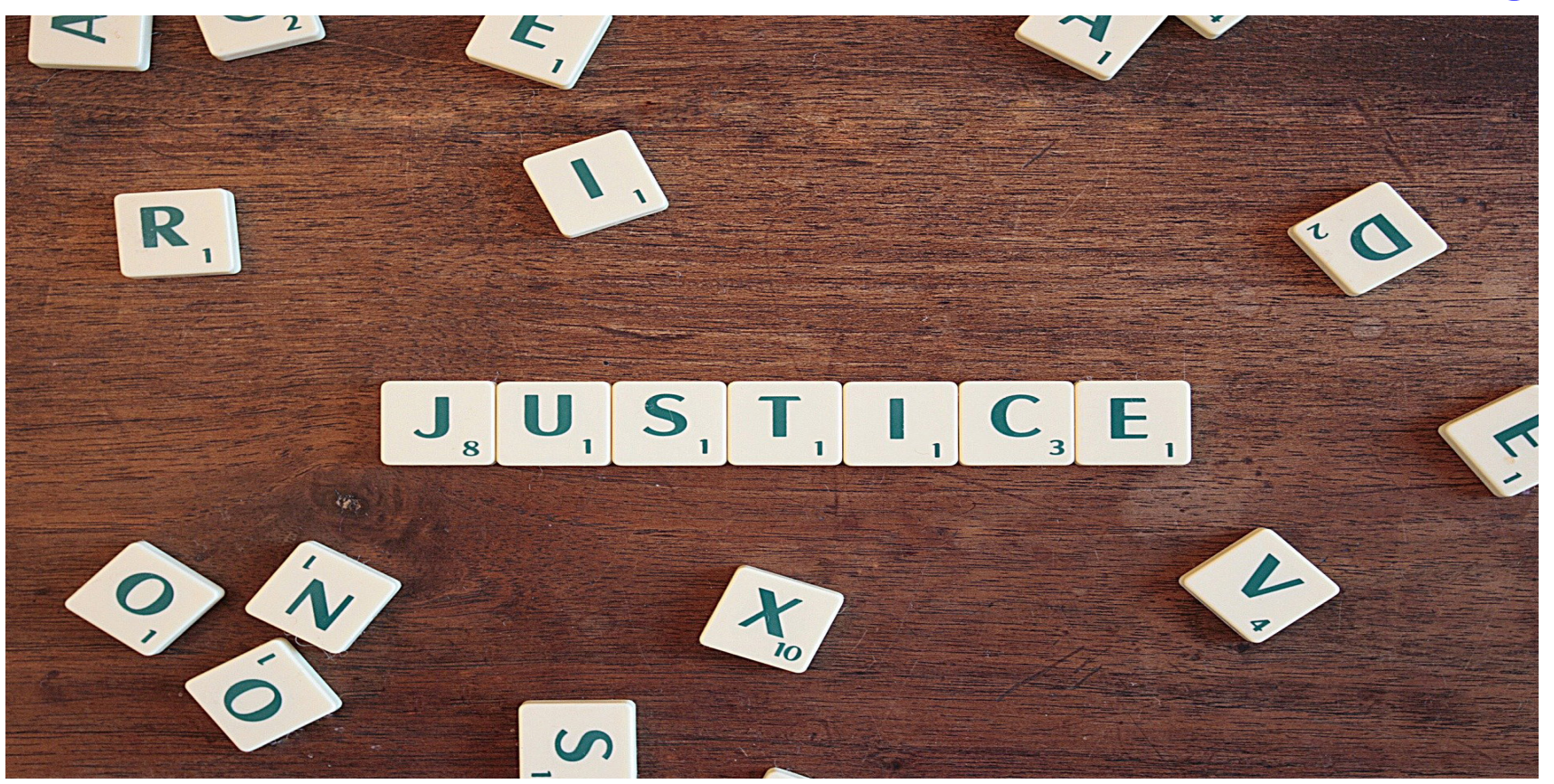

\title{
Recurso contencioso administrativo funcionarial en el proceso venezolano
}

\section{Functional administrative administrative remedy in the venezuelan process}

Adriana Bermúdez-Briceño

Abogado, Adriber21@hotmail.com.

https://orcid.org/0000-0002-0696-8106, Universidad Nacional

Experimental de la Fuerza Armada Nacional, Caracas,

Venezuela 
Resumen

La jurisdicción contencioso administrativa funcionarial, es la instancia que se encarga de controlar, vigilar y corregir, si es necesario, la actuación u omisión del Poder Público a través de sus distintos niveles, en lo referente a la relación laboral que lo vincula con los empleados. En la actualidad se pronuncian sentencias o decisiones judiciales en materia contencioso funcionarial que terminan de manera anormal el litigio; esto es, sentencias que se dictan sin analizar ni decidir sobre el fondo del asunto debatido. Esto puede afectar o perjudicar los derechos y beneficios que provienen de la relación de empleo público, cuyas consecuencias están dirigidos contra las personas que prestan sus servicios bajo la dependencia del EstadoVenezolano. Enestesentido, lainvestigación que se realizó busca impulsar el conocimiento en materia contencioso administrativa y así evitar la interposición del recurso funcionarial por parte de los empleados públicos; y evitar que sea resuelta de manera anómala; pues, de materializarse tal resolución anormal, impediría al Juez decidir sobre la reclamación o pretensión que impulsó al Aparato Jurisdiccional Tribunales en materia contencioso funcionarial.

Palabras clave: Acto administrativo, recurso funcionarial

\section{Abstract}

The administrative contentious administrative jurisdiction is the body that is in charge of controlling, monitoring and correcting, if necessary, the action or omission of the Public Power through its different levels, regarding the labor relationship that links it with employees. In at present, judgments or judicial decisions in contentious civil servants are pronounced that end the litigation abnormally; that is, sentences that are issued without analyzing or deciding on the merits of the matter under debate. This can affect or harm the rights and benefits that come from the public employment relationship, the consequences of which are directed against the people who provide their services under the dependency of the Venezuela State. In this sense, the investigation that was carried out seeks to promote knowledge in contentious administrative matters and thus avoid the filing of an official appeal by public employees; and prevent it from being resolved abnormally; Therefore, if such abnormal resolution were to materialize, it would prevent the Judge from deciding on the claim or claim that prompted the Courts Jurisdictional Apparatus in contentious civil matters.

Keywords: Administrative act, official resource 
Introducción

Según [1], todo grupo social merece estar constituido y esa dirección está a cargo del Estado; siendo éste, una unión de voluntades que se unen con el objetivo de obtener el bien público o general. Ahora bien, la manifestación de voluntad del Estado no es generada de un organismo con vida propia; sino que amerita de las personas naturales mediante las cuales pueda expresarse y actuar, individuos que estarán encargados de su representación, de su administración y de su operatividad. Así, las personas que ejercen la representación legal del Estado, asumen de manera fáctica y virtual el papel o rol de éste, con las facultades o potestades descritas en el ordenamiento jurídico.

Entonces, una vez que el Estado se vincula con las personas naturales para lograr sus propósitos, estos individuos le prestan sus servicios personales; momento en el cual se concibe la relación de empleo público o funcionarial. La figura jurídica denominada la relación estatutaria, fue explicada en el pensar de [2] cuando determina, que el Estado requiere de la labor del recurso humano para que exprese su manifestación de voluntad, y es allí cuando se vincula laboralmente con las personas que fungirán como Funcionarios Públicos en Venezuela.

Es por ello [3], deduce que dentro de la relación de empleo público entre el Estado y la persona, el ejercicio de la función pública si bien es materializada por una persona natural, sus actos hacen responsable al órgano público. La relación de empleo público o funcionarial posee los mismos elementos establecidos dentro de cualquier relación de trabajo, como son: La prestación del servicio personal, a entender cómo poner a disposición de un patrono las habilidades o destrezas que posee una persona. La subordinación, es cuando la labor o el trabajo se desarrolla bajo la dependencia; es decir, donde el sujeto que presta el servicio personal debe rendir cuentas a su empleador, y es éste último quien establece las normas e indicaciones de cómo se desarrollará dicho empleo.

La ajenidad, implica que, un sujeto materializa el hecho de prestar un servicio en favor y por cuenta de otro sujeto; aquí se identifica a las partes - empleador o patrono, y empleado o trabajador - del contrato de trabajo. El salario, es el derecho de percibir una contraprestación por la labor o el trabajo realizado; para el caso de los empleados o funcionarios públicos, este elemento se denomina remuneración, según la Ley del Estatuto de la Función Pública. Ahora bien, dado que la relación de empleo público o funcionarial se adecúa a los derechos y beneficios que se desprenden de cualquier otra relación laboral; el empleado púbico al ser objeto de cualquier acción u omisión por parte de la Administración Pública que implique el detrimento, el menoscabo o la afectación de los derechos y beneficios laborales, posee la acción judicial denominada el Recurso Contencioso Administrativo Funcionarial, con el propósito de que haga valer sus derechos o para el restablecimiento de la situación jurídica subjetiva infringida.

El recurso funcionarial, se tramita por ante los Órganos, en materia de lo contenciosoadministrativa funcionarial, cuyo procedimiento termina con el dictamen de una sentencia que resuelva el thema decidendum, la pretensión o el fondo del asunto debatido. Ello, en razón de que la Jurisdicción Contencioso Administrativa Funcionarial, faculta a los Órganos Jurisdiccionales especializados, para la vigilancia, el control y la corrección de ser el caso, del desempeño del Poder Público al subrogarse las veces de empleador o patrono en la relación de empleo público que mantiene con el Personal adscrito bajo su dependencia. A pesar de lo precedente, existen circunstancias por las cuales los Órganos Jurisdiccionales especializados procesan y terminan el proceso de los recursos funcionariales de 


\section{6}

forma irregular; esto es, por materializarse determinadas circunstancias de hecho que se subsumen en las circunstancias de derecho, lo que genera la imposibilidad o el veto al Juez para entrar analizar ni decidir sobre el fondo de la acción; lo que podría traer efectos o consecuencias adversas para las pretensiones del empleado o funcionario público.

\section{Desarrollo}

Según [4], la concepción del Estado tuvo como antecedentes a las primeras civilizaciones de Greciay de Roma; en Grecia, conla denominada Polis, es decir, era la unión de elementos como: El origen étnico, la lengua, la religión y la cultura; y en Roma, con la denominada Civitas, utilizado para definir a la extensión territorial de la ciudad, que luego fue llamada Res Pública, de ahí deviene la expresión República, cuyo significado implicaba, cosa común a todo el pueblo o a la comunidad de ciudadanos; para ese tiempo, el Estado como organización política de la sociedad reposaba en manos del Monarca, Rey, o Príncipe. Actualmente, el Estado, como organización política de un país; despliega su actuación a través de las distintas ramas del Poder Público, bien sea desde el punto de vista horizontal (Ejecutivo, Legislativo y Judicial), o mediante la escala vertical (Nacional, Estadal y Municipal).

Así, ese proceder debe generarse en base a un sustento normativo, cuyo compendio está concebido en la Constitución, y de la cual se desarrolla el cuerpo legal para cada ámbito de aplicación del Poder Público; ello, implica el Principio de Legalidad de los Actos, de acuerdo a lo esbozado por [5]. Aunado a lo precedente, señala que, cada una de las ramas mediante las cuales se pronuncia el Estado, son contentivas de la delimitación de sus competencias, así como son poseedoras de la autonomía para conocer, instruir y emitir la manifestación de voluntad de la Administración o del Poder Público, que comprende el Principio de la Independencia o Autonomía, lo que también implica el Principio del Carácter Interorgánico de la Administración Pública.

En sintonía con [5], el Derecho Administrativo, ha sido creado como el conjunto de normas reguladoras a las cuales se debe someter los ciudadanos y el Estado, para con ello establecer las relaciones entre los administrados y la Administración Pública. Al hablar del origen del derecho administrativo se encontró que, su cimiento está referido al advenimiento del Estado de Derecho, el cual se funda en que la actuación del Estado está sujeta al imperio de la ley cuya norma está encabezada por la Constitución; y donde también, se garantiza la igualdad y la libertad de los ciudadanos.

De acuerdo [6-8] con la historia universal, el Estado de Derecho, tuvo lugar con ocasión de la llamada Revolución Francesa (1789); situación que acaeció en Francia, bajo el mandato del Rey Luis XVI, persona en la cual convergía el mando absoluto de ese país, donde la ley era la palabra del rey; revolución que conllevó, entre otros, a la Declaración de los Derechos del Hombre y del Ciudadano, donde el individuo o la persona se constituyó en el centro de atención, garantizándole sus derechos intrínsecos; además, se aprobó la primera Constitución de Francia, y se estableció la división e independencia de los poderes del Estado.

Dentro de los diversos aportes que se producen para la consagración del Estado de Derecho, está la noción del procedimiento administrativo. Ahora bien, para [9] infiere que fue en Austria, donde se gestó la idea de que el procedimiento administrativo, consistente en una secuencia o sucesión de actos regulados por una norma, tenía como fin último la emanación de un acto administrativo; entendiéndose como acto administrativo aquella manifestación de voluntad, fallo, resolución o dictamen, que emitía la Administración para regular un caso, el cual producía efectos jurídicos inmediatos. 
Bajo el análisis de [10], el origen del Derecho Administrativo en Venezuela, tiene relación con la concepción del Estado Venezolano, que tuvo lugar con la primera Carta Magna de 1811; donde además, se originó el control jurisdiccional de los Poderes Públicos, cuando estableció la nulidad absoluta de cualquier ley que se expidiese en contra de la Constitución. Y, en el Texto Constitucional de 1830 , se previó entre las atribuciones de la Corte Suprema, la providencia sobre la responsabilidad individual -civil y penal- que por mal desempeño en el ejercicio de sus funciones se exija de los funcionarios públicos; constituyendo el primer eslabón de la jurisdicción contenciosoadministrativa.

Si bien cierto, la justicia administrativa ha sido prevista de manera expresa en dos Constituciones de la República Bolivariana de Venezuela, tal y como lo explicó la Sala Constitucional del Tribunal Supremo de Justicia fallo publicado el 08/07/2013, expediente $\mathrm{N}^{\circ}$ 12-0911, sentencia $N^{\circ}$ 873; la denominada Jurisdicción Contencioso Administrativa, apareció expresamentela Constitución de 1961; luego, con la promulgación de la Constitución de 1999, se contempló dicha jurisdicción. Pero, el control jurisdiccional en materia contencioso administrativa, no se limita en vigilar, controlar y corregir de ser el caso, el actuar del Poder Público con el administrado; sino que, también implica la poder de examinar y fiscalizar tanto los maneras como los actos administrativos que emite la Administración en la relación de trabajo con los empleados dependientes de ella.

Ahora bien, sobre la base de lo dispuesto en la Ley del Estatuto de la Función Pública, el funcionario o empleado bajo la dependencia del Estado, en las distintas ramas del poder público; posee la acción judicial ante cualquier comportamiento de la Administración Pública que implique el detrimento de los derechos y de los beneficios derivados de la relación de empleo público. De acuerdo a lo anterior, el funcionario o empleado público afectado por la acción u omisión del patrono es decir el Estado, tiene la potestad de ejercer la acción en materia contencioso-administrativa funcionarial y con ello, hacer que los Órganos Jurisdiccionales Funcionariales en materia contencioso administrativa funcionarial, controlen, vigilen y corrijan dicho comportamiento.

El trabajo a desarrollar se concibió en razón de la ocurrencia de algunas circunstancias que generaron acontecimientos, dentro de las polémicas judiciales, que se suscitan específicamente en la jurisdicción contencioso-administrativa funcionarial. Esto es, ante la activación del aparato jurisdiccional por la interposición del recurso funcionarial de los empleados o funcionarios bajo la dependencia del Estado, con el objeto de reclamar los beneficios y los derechos que se derivan de la relación de empleo público o de la relación funcionarial. En este sentido [9] manifiesta que un número considerable de las acciones de índole funcionarial terminan por parte del Tribunal de manera irregular; en otras palabras, las recursos funcionariales concluyen con un fallo que no analiza ni decide el fondo de la causa o del objeto controvertido, y en consecuencia, el proceso en ese litigio, finaliza.

Por ello, para un mejor entendimiento del objeto de estudio, se propone su análisis mediante la implantación del método cualitativo, y con el conocimiento a obtener, se logrará la construcción de nuevas situaciones que puedan modificar o alterar los eventos no deseados que generaron esos fenómenos.

Bajo el pensamiento de [11] los entornos de la investigación, componen los estudios que antecedieron referentes a la cuestión que se trata investigar, y muestran los avances y la comprensión que para ese tiempo fueron explícitos con el hecho que se investiga; precediendo una exigencia precisa en el vínculo. 


\section{8}

Adicionalmente, es legítimo advertir que, la investigación a realizarse, estriba en fomentar el conocimiento sobre la norma judicial inherente a la relación de empleo público o relación funcionarial habida entre el Estado (empleador-patrono) y el servidor público (empleado-trabajador), cuando en dicha relación laboral se afectan los derechos e intereses de la parte más vulnerable 0 débil jurídico como lo es el trabajador.

Existen situaciones relevantes a nivel internacional: para [12], enseñó sobre la responsabilidad en el ejercicio de los cargos públicos; se instruye como concepción de la Administración, aquél aparato adscrito al Estado que se enlaza con la sociedad civil, y donde uno de sus objetivos consiste en solucionar los problemas no crearlos, además de promover el desarrollo y la paz social. Igualmente se revela, que la buena Administración debe avalar los principios de igualdad, seguridad jurídica y legalidad; y además implica, el servicio a los intereses generales.

Como es indicado por [12], la buena Administración debe garantizar: 1) El derecho de ser escuchado y el aseguramiento de la igualdad de las partes; así mismo, los interesados, tienen derecho a conocer el estado de tramitación de los procedimientos y solicitudes 2) El acceso de todos los ciudadanos a los archivos y registros administrativos, con los límites establecidos por seguridad nacional. 3) El derecho de toda persona a ser indemnizada, por cualquier lesión generada en sus bienes o derechos como consecuencia del funcionamiento de los servicios públicos, salvo en los casos de fuerza mayor. 4) El derecho a ser juzgado por un tribunal imparcial, a través de un proceso equitativo y sin dilaciones indebidas. 5) El derecho a una resolución administrativa motivada.
El funcionario público debe dar su tiempo, sus esfuerzos y respuestas con la rectitud, atención y premura, en favor del administrado o particular; esto, compone el servicio público, sin dar cabida a los intereses ilegítimos. La transparencia: El ejercicio de un cargo público no debe permitir la falsedad, ni encubrir datos relativos a la gestión pública. A mayor abundancia sobre el principio de transparencia, referente a los preceptos éticos que deben ser innatos en el personal de la buena Administración.

De este modo [12], apunta, a pesar de que la Administración tiene mala reputación, pues, cualquier trámite administrativo es una ofensa ante un desagradable y lento trámite; es necesario mediante el cambio forjar un buen gobierno y con ello, una buena Administración Pública. Pero ese cambio no es exclusivo de los políticos y funcionarios; sino que involucra a la sociedad en su roll de pueblo soberano cuyo núcleo es la familia, quien debe preocuparse y luchar por sus derechos; esto, en razón de que, cuando la sociedad participa en la elección de un gobierno, confía en que los miembros del Poder Público cumplan y busquen siempre actuar en pro del interés de la comunidad. En este sentido se enaltece la conducta del funcionario público en el ejercicio del cargo bajo la dependencia de la Administración Pública; y de lo plausible que es contar con la legislación que establezca el modo de actuar del recurso humano adscrito a la función pública. En Venezuela existe el Código de Ética de las Servidoras y los Servidores Públicos, establece deberes y obligaciones del funcionario al servicio del Poder Público.

Por su parte [13]; esbozó sobre el funcionario y la función pública, para lo cual señaló que, el calificativo de funcionario ostentaba las siguientes variantes: La primera modalidad, corresponde a los denominados Funcionarios de Carrera, son aquellas personas que fueron nombradas legalmente para el desempeño 
de servicios profesionales de carácter permanente, y quienes están vinculados a la Administración Pública, cuya relación legal está regulada por el Derecho Administrativo. La segunda modalidad, atribuida a los designados como Funcionarios Interinos, está integrada por el personal de confianza política, cuya relación estatutaria está regulada por el régimen general de los funcionarios de carrera, en cuanto se adecue a su condición laboral. La tercera modalidad, está constituida por el Personal Laboral, ya sea: Fijo, por tiempo indefinido, o temporal. La cuarta modalidad, incluye al trabajador Eventual o Contratado.

Ahora bien, la diferencia principal entre la primeray lasegundamodalidad defuncionarios, estriba en la estabilidad en la Administración. Según el enfoque de [13], las condiciones para considerar como legal el nombramiento de un funcionario, son: 1) La disposición inmediata de la ley, en un principio no se permitía dicha disposición a través de una norma de rango jerárquico inferior (reglamentos, órdenes); sin embargo, según la doctrina actual, esa exigencia fue disminuida al contexto de que, el ente al cual se incorpore el funcionario debe establecer la necesidad del personal mediante la resolución u orden ministerial respectiva, la cual debe ser publicada en el Boletín Oficial del Estado (BOE), actuación que constituye una formalidad. 2) El trámite del procedimiento de elección del posible funcionario. 3) El nombramiento del funcionario por parte de la autoridad competente. En otro aspecto, el autor aludido reveló que, la función pública, comprende aquella actividad material o jurídica que procede directa o indirectamente de la Administración.

De esta manera, cuando se hace referencia a las funciones públicas, deben concurrir tres (3) premisas: 1) El elemento subjetivo, o sea, la función pública, es la actividad realizada por un ente público. 2) El elemento objetivo, implica que la función pública, es la actividad realizada mediante actos sometidos al derecho público. 3) El elemento teleológico, concierne a que la función pública, es aquella que persigue fines o intereses públicos. Según [13], el Código Penal de España, considera como funcionario público, a toda persona que por disposición inmediata de la ley, por elección popular o por nombramiento de la autoridad competente, participe en el ejercicio de la función pública. Igualmente, se incluye en dicho código, el Título relativo a los Delitos de los Empleados Públicos en el ejercicio de sus cargos. En este sentido, piensa [13] que, el Derecho Penal reglamentó una serie de conductas ilícitas realizadas por los funcionarios adscritos a la Administración; y la jurisprudencia ha establecido que, si bien existen empresas de derecho privado que realizan la actividad de los servicios públicos, o particulares concesionarios de servicios públicos, éstas son en realidad órganos públicos que desarrollan funciones de interés público, y ante tal condición, serían juzgados por sus actuaciones al margen de la ley.

El aporte que hace [13], está determinado a que tanto en España como en Venezuela, existen distintas modalidades de empleado bajo la dependencia del Estado, como son: Los empleados de carrera, los empleados contratados o temporales, y los empleados de confianza; y dependiendo de la condición del funcionario será su estabilidad laboral. Además, dicho autor también concibe como en Venezuela, que el empleado público tiene responsabilidad en el ejercicio del cargo público que desempeña. [14] narró sobre el proceso judicial como se reproduce a continuación: el proceso es una serie de actos que se despliegan gradualmente, con el objeto de solucionar, mediante un juicio de la autoridad, el conflicto sometido a su decisión. Lo que determina al proceso es su fin; el fallo del conflicto mediante una sentencia que adquiere autoridad de cosa juzgada y en este sentido, proceso semeja a litigio.

El proceso, es la totalidad de los actos por medio de los cuales se constituye, se desarrolla y termina la relación jurídica. 


\section{0}

Mientras, el procedimiento, es la manera o forma en que se exteriorizan los actos que se desarrollan en el proceso. En razón [14], el juez construye la sentencia para concretar la justicia en cada caso. De acuerdo con el discernimiento de la autora en referencia, en el juicio ordinario de la legislación de Francia, luego terminadas las alegaciones se dicta sentencia en base a la fundamentación, y el fallo abarca el encabezado y los antecedentes de hecho, posteriormente la sentencia produce la cosa juzgada. Es relevante destacar que este contenido establece que el proceso judicial tiene como objetivo la emisión del acto procesal final conformado por la sentencia que disipe la petición que activó la vía judicial y que fue objeto de controversia durante la vigencia del proceso.

Según [15] argumentó, que la jurisdicción advierte aquel proceso de conocimiento del juez, cuya etapa final está limitada en una sentencia que se pronuncia sobre la procedencia o no de la pretensión interpuesta; según el autor, existen situaciones donde el sentencia del juez no involucra el estudio de la petición y expresa un fallo por el cual acaba el proceso. De acuerdo a [15], la terminación anormal del proceso, extinción del proceso o modos excepcionales que ponen término a la relación procesal, implican hechos jurídicos y actos jurídicos que modifican la realidad jurídica procesal provocando la extinción del proceso. Se evidencia un aporte que existe dentro de la jurisdicción, la forma normal y los modos no habituales para la terminación del proceso en una acción judicial.

Para [16], hace referencia a la Carta Magna, donde se consagran los valores éticos que han de estar presentes en la actuación de los funcionarios públicos, pues, son ellos quienes conforman la sujeción entre la actividad del Estado y los requerimientos de la ciudadanía. Desde el pensamiento [16], los valores éticos se revisten como estructuras normativas para la mejor convivencia dentro de la sociedad en sus distintos ámbitos. Y, en el caso del Estado, del Poder Público o de la Administración Pública, cuya autoridad se dispersa mediante los entes y órganos públicos, dichos valores corresponden abarcar: La probidad, la eficacia, la eficiencia, la transparencia, la excelencia y la responsabilidad; todo ello, para dirigirse en la prestación de un servicio público óptimo y armónico. [17], destaca: la responsabilidad social debe ser la respuesta asertiva del personal adscrito al Estado; esto, por ser dicho recurso humano el vínculo entre la actuación del Estado y las presunciones de los ciudadanos; y es a través del servicio público, que se conseguirá ayudar con la complacencia de los intereses generales e individuales que deben ser asegurados a la sociedad.

Así, los valores éticos de todo empleado adjunto a la Administración Pública, son una variable concluyente en su comportamiento y en sus acciones, lo que se va a traducir como el servicio público, actuación que trae intrínseca los patrones de conducta que deben generarse en favor del interés público.

El aporte que hace [16] plantea, el personal funge como el Servidor Público, cuyos valores éticos deben serle intrínsecos, y donde su objetivo es el servicio a la comunidad para la satisfacción de sus requerimientos. De la misma manera [17], destacó que, la regulación profesional de empleo público está dispuesta en la Ley del Estatuto de la Función Pública, cuyo vínculo fue denominado como empleador-servidor. Al respecto, el funcionario interviene como un colaborador en el resultado de los fines públicos, y donde el ejercicio del cargo alcanza deberes preconstituidos a ese ejercicio; pero, al ser ignorados conllevan a la responsabilidad individual del empleado público en los ámbitos civil, penal, administrativo, político y disciplinario. De ahí que, el Poder Público a través de sus órganos aplicó medidas de conducta que preparan la actuación de la gestión del funcionario público, 
y la transgresión de dicha normativa conlleva a la obligación de sanciones disciplinarias o administrativas tal como lo establece la Ley especial y que están antecedidas por el procedimiento administrativo disciplinario; es decir, la Administración está salvaguardada del ejercicio del poder punitivo sancionatorio. Adicionalmente, en dicho procedimiento se debe garantizar los Principios Constitucionales como el Derecho a la Defensa y el Debido Proceso. El objetivo del procedimiento disciplinario, de acuerdo a la doctrina de [18], es corregir la falta en que haya realizado el funcionario, y así corregir la no reincidencia del comportamiento contrario a la ley. Aporta que el poder punitivo que posee el Estado Venezolano existe y determina la responsabilidad de los funcionarios que le son adscrito, cuando la conducta o comportamiento, o los deberes de éstos, van en quebranto de los derechos, bienes e intereses de la Nación; pues, ese actuar está al margen de lo dispuesto por la normativa que los regula, y cuya base reposa en la Ley del Estatuto de la Función Pública. Dentro de este marco [19], en la cual se indicó que, si bien, la Constitución de la República Bolivariana de Venezuela de 1999, preveía como mecanismo de ingreso a la Administración Pública el concurso público, de acuerdo a lo establecido por la Ley del Estatuto de la Función Pública. Sin embargo, para [16], la legislación permitía al Estado recurrir a la figura del personal contratado con el propósito de atender las urgencias procedentes del ejercicio de la función pública institucional, es decir, obtener una mayor efectividad de la gestión gubernamental. Bajo esa opinión, a pesar de que la condición de contratado está subordinada precisamente a un tiempo determinado; no obstante, aun en la Administración existe la práctica de proveer cargos en condición de contratados que se mantiene por tiempo indeterminado, aludiéndose la materialización del proceso al concurso público. Esa situación irregular ha sido catalogada como relación funcionarial encubierta.
En consonancia de la posición aludida, el contrato laboral temporal es caracterizado por ser escrito, voluntario, preciso al establecer los objetivos o las funciones, y determinable al indicar el tiempo de vigencia del contrato; todo de conformidad con las normas previstas en la Constitución y en la legislación laboral. Y, aun cuando se evidencie la culminación del contrato laboral, y existe la posibilidad de prorrogarlo, esa estabilidad laboral no es absoluta, ni progresiva. [19] refieren, la Carga Magna prevé que, los cargos en la Administración Pública son de carrera, exceptuando: Los de elección popular, los de libre nombramiento y remoción, los contratados y obreros.

De igual manera aseveran, la Constitución dispone que, el ingreso de los funcionarios públicos a los cargos de carrera está supeditado a la realización y aprobación del concurso público. A esa exigencia, se une la prohibición plasmada en la Ley de Estatuto de la Función Pública, cuando establece que, la condición de personal contratado no debe constituirse en una vía de ingreso en la Administración Pública. Continúan argumentando [19] el Ministerio del Poder Popular para la Planificación y Finanzas, emitió los lineamientos para el tratamiento uniforme del personal contratado por la Administración Pública, contenido en la Circular $N^{\circ} 029$, de fecha 19/01/2004, a través de la cual dispuso que, el periodo de contratación no debe superar los tres (3) años de servicio. Lo que quiere decir que, la concordancia entre el contratado y el Poder Público es inevitable, pues, su acción permite dar acatamiento a las proyecciones planificadas en la gestión pública, y donde el contratado elaborará las actividades para las cuales fue contratado y que no conste el personal permanente.

La [19]; señaló que, el Sistema Nacional de Control Fiscal, es el órgano comisionado para indagar la acciones de los funcionarios, cuya responsabilidad procede de las faltas, actos, hechos u omisiones no conformes 
a la legislación sobre la dirección de los patrimonios públicos. El Funcionario Público, es el que se desempeña sus funciones en un órgano del Estado, y es esa actuación lo que comprende los intereses generales.

Este argumento, revela que la actitud del empleado público sobrelleve a la desorganización de sus atribuciones, o a la contravención de sus obligaciones; no basta con derogar los actos contrarios a derecho, sino que es loable la aplicación de sanciones de distintos órdenes; en virtud de que los funcionarios son los empleados que desempeñan y concretan las funciones del Estado. La responsabilidad administrativa sólo abarca al empleado en sus funciones, no se extiende a su patrimonio ni a su persona; por lo que la responsabilidad administrativa abarca actos administrativos, o conductas de hacer y no hacer.

Sobre lo expuesto [19], es de la opinión que, al suceder alguna actuación a la normativa conductual del empleado público, el Sistema Nacional de Control Fiscal, lleva a cabo el procedimiento administrativo para emitir o no la responsabilidad del funcionario. Bajo el enfoque [19], el procedimiento administrativo de responsabilidad, está determinado en la Ley Orgánica de la Contraloría General de la República, del Procedimiento Administrativo para la Determinación de Responsabilidades, esta norma anuncia que los órganos de control, vigilancia y fiscalización de la Contraloría General de la República, descansa en cada ente u órgano adscrito al Poder Público. Ahora bien, el procedimiento administrativo de responsabilidad debe tramitarse según lo regulado en la Ley Orgánica de Procedimientos administrativos, y todas las actuaciones deben en centrarse en un expediente administrativo. Acabado el procedimiento administrativo con el pronunciamiento de la manifestación de voluntad, de juicio o de conocimiento del Estado de la Administración Pública; el funcionario público tiene el libre derecho para interponer por ante la misma Administración, el recurso de reconsideración; o plantear el recurso de nulidad, el recurso contencioso administrativo funcionarial por ante los órganos jurisdiccionales (Tribunales de lo Contencioso-Administrativo) respectivos.

Es indicado por [20] que, la manifestación de voluntad, de juicio o de conocimiento del Poder Público se materializa mediante el dictamen de un acto administrativo, dicha manifestación debe cumplir las exigencias determinadas en la Ley Orgánica de Procedimientos Administrativos y además, debe ser notificado y firmado por su receptor. Sin embargo, con la implementación de la Administración Pública electrónica, que involucra el acto administrativo electrónico; este último, discrepa con el acto administrativo tradicional por el medio o soporte material de su emisión o transmisión. Bajo esta actitud, para [20] las actuaciones en la Administración Pública electrónica tengan eficacia y validez, deben cumplir los requerimientos establecidos en el Decreto con Rango, Valor y Fuerza de Ley Sobre Acceso e Intercambio Electrónico de Datos, Información y Documentos Entre los Órganos y Entes del Estado (Ley de Interoperabilidad). El Tribunal Supremo de Justicia, sigue discerniendo en cuanto a la aplicabilidad de la Administración Pública electrónica y sus actuaciones.

En este sentido, [20] surge, hay exigencias de validez del acto administrativo tradicional, que no pueden trasladarse al formato electrónico; y el mensaje de datos recibido a través del correo electrónico, es solo una simple participación o medio de comunicación del acto administrativo formal. Por tal razón, dicha el Tribunal Supremo de Justica, estableció que el instante en que debe considerarse notificado al particular del respectivo acto administrativo, es desde el momento en que éste acuda a la Administración y le sea entregado el íntegro del acto administrativo en cuestión. 
De ahí se arribó a la presunción que, la tecnología informática implementada mediante las TIC, ofrece el avance para que sea utilizado tanto por el Estado como por los ciudadanos. Los medios probatorios electrónicos deben ser apreciados, siempre y cuando exista la firma (sea autógrafa o electrónica en el documento); pues, esta circunstancia genera su autenticidad, y dará fe de quien lo firmó y del contenido de su autoría. En la actualidad, los actos administrativos electrónicos se ven afectados en sus elementos de forma, mas no en los elementos de fondo; circunstancias ésta, que la norma venezolana ha ido asimilando pausadamente.

Arguye [20] que, las TIC en el ámbito administrativo electrónico, llevan a la mejoría en la prestación de los servicios públicos y a las actividades administrativas del Estado, en la Administración Pública, lo cual conlleva: La celeridad en las actuaciones, economía, transparencia, eficacia y eficiencia en las tramitaciones y decisiones; ello, soporta a producir el ahorro de tiempo en los ciudadanos y a la Administración Pública.

El Poder Público debe ir de la mano con los progresos informáticos y de comunicación; ya que el Estado conserva una relación administrativa perdurable con los ciudadanos, busca que esa forma sea lo más eficaz y eficiente posible. En este sentido, el Estado se está valiendo de la plataforma cibernética y de las redes de comunicación interconectadas de nombre World Wide Web (WWW o la Web), para hacer que su comunicación y respuesta con el particular sea más rápida, eficiente y eficaz.

Los Modos de concluir de manera Anormal el Proceso

Por su parte [21], establecen que la jurisdicción argumentaron que la tutela jurisdiccional no solo alcanza el derecho de las personas de adherirse al proceso judicial, sino que también abarca, que la pretensión judicial desemboque en la decisión jurisdiccional.

El proceso entra en dificultades cuando por alguna razón surge la imposibilidad de realizar en su momento el acto procesal que el mismo requiere; es decir, cuando la incidente ocurre causa sobrevenida y se opone a la ejecución de uno o de algunos actos, haciendo detener la continuación del proceso en su totalidad. Esto, se contrapone al desarrollo normal del proceso donde la actividad procesal continúa en su momento oportuno.

El Recurso Contencioso Administrativo Funcionarial, compone la acción judicial a la orden de los funcionarios adscritos a la Administración Pública, cuyo procedimiento está contenido en la Norma ContenciosoAdministrativa Funcionariales decir, en la Ley del Estatuto de la Función Pública.

Con respecto [21] El Estado Venezolano como organización política, extiende su acción a través de las diferentes ramas del Poder Público, Así, ese proceder debe crearse en base a un apoyo normativo, cuyo resumen está concebido en la Constitución de la República Bolivariana de Venezuela, y en la cual se desarrolla el cuerpo legal para cada ámbito de aplicación del Poder Público; ello, implica el Principio de Legalidad de los Actos.

Además, posee la delimitación de las competencias, así como la autonomía para conocer, instruir y emitir la manifestación de voluntad de la Administración o del Poder Público, que comprende el Principio de la Independencia o Autonomía; es decir es el conjunto de normas reguladoras a las cuales se debe someter los ciudadanos y el Estado, para con ello establecer las relaciones entre los administrados y la Administración Pública.

Igualmente,[22], consideraqueelProcedimiento Administrativo, es el medio procesal donde 


\section{4}

se debe garantizar y proteger los derechos e intereses intrínsecos de los administrados dentro de la administración pública; esto, para impedir la injusticia en la actuación del Estado y el desamparo de las personas en dicha interacción; procedimiento que concluye con la emisión de un acto administrativo definitivo, que representa la manifestación de voluntad del Poder Público, dictamen que está expuesto a ser contradicho, objetado o examinado mediante el control judicial en los Tribunales de lo Contencioso Administrativo.

El control jurisdiccional en materia contencioso administrativo, no se limita en el actuar del Poder Público con el particular; sino que además implica la potestad de revisar y controlar tanto los procedimientos como los actos administrativos que emite la Administración dentro de su relación laboral con los empleados subordinados a ella. De ahí que, la Constitución estableció que el ingreso, ascenso, traslado, suspensión y retiro de dichos empleados, sería normado por la Ley del Estatuto de la Función Pública. Es importante resaltar que nuestra Carta Magna, garantiza al trabajador, condiciones laborales eficaces en su entorno; y vigila la protección de su estabilidad y el reconocimiento de los beneficios que se deriven del vínculo de trabajo.

Regulado el vínculo funcionarial que concierne como patrono al Estado y como trabajador a los funcionarios; es notable indicar que, no toda persona que resida en el país puede desempeñarse como funcionario adjuntado a la Administración Pública. Pues, la función pública involucra el manejo de derechos, bienes e intereses del Estado, de entre los cuales podemos indicar: Presidente de la República. La administración de justicia (Magistrados del Poder Judicial). Personal Militar de las Fuerzas Armadas. La actuación ante el comisión de un hecho punible, Fiscales del Ministerio Público. La administración y gerencia de los Estados y Municipios (Gobernadores y Alcaldes); entre otros.

Argumenta [18] , que empleados o funcionarios públicos tienen la potestad de ejercer la acción en materia contencioso-administrativa funcionarial, señalada como el Recurso Contencioso Administrativo Funcionarial; acción referida por el Tribunal Supremo de Justicia en Sala Constitucional, fallo publicado el 12/11/2015, Exp. № 18-1012, sentencia № 14826 , la cual a su parecer deja clara, que, las escenarios laborales que se susciten dentro de la relación de empleo funcionarial o de empleo público, que afecte los derechos e intereses del empleado o funcionario; deben señalarse mediante la instauración de la acción designada la Ley del Estatuto de la Función Pública, es decir, el recurso contencioso administrativo funcionarial; y deben ser tramitadas según el procedimiento judicial establecido por la Ley del Estatuto de la Función Pública . Así, la acción judicial que persigue acometer no solo una manifestación de voluntad expresada del Poder Público por medio del acto administrativo definitivo de efectos particulares o individuales; acto en el cual se le imputa una sanción disciplinaria administrativa contra el funcionario investigado, como por ejemplo, la destitución del cargo. Sino además, dicha acción es el medio jurídico idóneo para impugnar cualquier omisión que se desprenda de la Administración Pública, que vaya en menoscabo de los derechos o beneficios de la relación de empleo público, como por ejemplo, el no otorgamiento de la jubilación, previo el cumplimiento de las exigencias de ley.

La Ley Orgánica del Tribunal Supremo de Justicia, determina las competencias de cada una de las Salas que conforman el Tribunal Supremo de Justicia, donde el pico de la Jurisdicción ContenciosoAdministrativa reposa en manos de la Sala Político- Administrativa. Igualmente, es importante destacar que, la Ley Orgánica de 
la Jurisdicción Contencioso Administrativa, señala las competencias o atribuciones de cada uno de los órganos que componen la Jurisdicción Contencioso Administrativa; todo lo cual está contemplado en el Título II De la Estructura Orgánica de la Jurisdicción Contencioso Administrativa, y en el Título III De la Competencia de los Órganos de la Jurisdicción Contencioso Administrativa.

Ahora [22]. Manifiesta que la Ley del Estatuto de la Función Pública, es la que reglamenta la relación de empleo público o funcionarial habida entre la Administración Pública Nacional, Estadal y Municipal con los funcionarios, empleados o servidores públicos. La Ley del Estatuto de la Función Pública prevé que, ante el acontecimiento de actuaciones que confluyan en: Delitos, faltas, hechos ilícitos e irregularidades administrativas, durante el ejercicio del cargo o de las funciones públicas, el funcionario será objeto de la investigación que determine la responsabilidad civil, penal, administrativa y disciplinaria; donde esta última prevé como sanciones: La amonestación escrita, y la destitución. En el Título VI Responsabilidades y Régimen Disciplinario, Capítulo III Procedimiento Disciplinario de Destitución, se estipula todas las fases y actos que integran el procedimiento administrativo disciplinario contra el funcionario investigado. A su vez, en la instancia administrativa, el procedimiento disciplinario o sancionatorio que el ente u órgano al cual está designado el funcionario investigado, está conformado por varias etapas como: La instauración, la tramitación o sustanciación, la decisión, y la ejecución del acto administrativo definitivo que establezca la sanción administrativa o disciplinaria; acto que debe ser notificado a la parte afectada.

A través de la siguiente investigación se viene a desarrollar los objetivos específicos contenidos:
- Interpretar sobre quienes pueden activar recurso contencioso administrativo funcionarial.

- Describir las maneras anómalas que terminan el proceso en los recurso contencioso administrativo funcionarial.

Durante la vigencia de la relación de empleo público o funcionarial, acontecen ciertas situaciones que involucran a un funcionario, las cuales ameritan sean resueltas previo el trámite del procedimiento disciplinario sancionatorio o de destitución, según lo dispuesto en los artículos 89 y siguientes de la Ley del Estatuto de la Función Pública. En otras palabras, cuando el Estado Venezolano a través de sus distintos entes u órganos del Poder Público, estime que un funcionario estuviere incurso en una causal de destitución, debe proceder a la apertura de la investigación para determinar la responsabilidad administrativa del funcionario y establecer las sanciones pertinentes.

Se entiende que, ante cualquier situación de hecho considerada por la Administración Pública como incumplimiento de los deberes inherentes al cargo por parte del funcionario, se debe procederse a iniciar, tramitar, sustanciar y resolver la averiguación disciplinaria respectiva; ello, para garantizar en cualquier vía -administrativa y judicial- los derechos establecidos en la Constitución de la República Bolivariana de Venezuela, como son: El debido proceso y el derecho a la defensa.

Lo antes indicado, tiene cabida sobre la base de la estabilidad laboral con que cuenta el funcionario de carrera.

No obstante, para el caso en que el funcionario sea de libre nombramiento y remoción, no le es aplicable la protección del previo procedimiento disciplinario sancionatorio o de destitución, para que la Administración Pública resuelva sobre la remoción y el retiro posterior de dicho 
funcionario; pues, esa condición no goza de estabilidad laboral.

Para [23], considera que la cualidad ha sido bien definida por el Máximo Tribunal de la República en Sala Político-Administrativa, fallo publicado el 02/06/2016, expediente $\mathrm{N}^{\circ}$ 009-0121, sentencia $\mathrm{N}^{\circ} 00513$, cuando constituye que la cualidad es la aptitud jurídica que posee determinada persona -sea natural o jurídica- para constituir cualquiera de los sujetos procesales dentro de un litigio judicial. Así, la cualidad contempla dos (2) vertientes: La condición o legitimatio ad causam activa, y la condición o legitimatio ad causam pasiva. Concibe que la condición o legitimatio ad causam activa, encarna la titularidad que posee cierta persona -sea natural o jurídicapara el ejercicio del derecho de acción.

Mientras, la cualidad o legitimatio ad causam pasiva, implica la titularidad que posee una persona para que acude y active un proceso judicial como el sujeto procesal denominado: Agraviante.

Ahora bien, [22] cuando se señala la cualidad para interponer el recurso contencioso administrativo funcionarial; se refiere a la condición que debe poseer el personal adscrito o bajo la dependencia del Estado Venezolano en cualquiera de sus niveles, sea horizontal o vertical. Para ello, se amerita establecer la naturaleza del cargo que ejerce el individuo que labora para la Administración Pública; pues, aun cuando en la nómina pública haya una gran cantidad de personal bajo su dirección, orden o disposición, no toda persona que se desempeñe para el Estado tiene la aptitud para interponer el recurso funcionarial.

Las maneras anómalas que terminan el proceso en los recursos funcionariales.

La Carta Magna [24] prevé: El proceso constituye un instrumento fundamental para la realización de la justicia... es decir, el proceso, es la garantía constitucional mediante la cual se pone en conocimiento de determinada autoridad -administrativa o judicial, la leyun conflicto que vincula a distintas personas -naturales 0 jurídicas- por tener intereses comunes o diferentes; esto, con la finalidad de que dicha autoridad resuelva sobre el tema de lo controvertido a través de la emisión de un fallo, decisión o sentencia.

Siguiendo [21], también existen circunstancias que acarrean que el dictamen del juez no implica el análisis de la pretensión por el cual termina el proceso; pues, dichas circunstancias conllevan a la terminación anormal del proceso, extinción no habitual del proceso o modos excepcionales que ponen término a la relación procesal, esas circunstancias implican hechos jurídicos y actos jurídicos que afectan de tal modo al proceso judicial que genera su extinción de forma irregular. En lo que concierne a la noción sobre los hechos jurídicos, [22] el hecho jurídico es todo acontecimiento al que el ordenamiento imputa la virtud de producir por sí o en unión de otros un efecto jurídico, es decir, el provecho, la pérdida o la transformación de un derecho, respecto a la idea sobre los actos jurídicos, presume un hecho humano producido por voluntad consciente y exteriorizada que causa un efecto jurídico

Así las cosas, se tiene que, dentro del proceso judicial pueden acaecer tanto hechos jurídicos como actos jurídicos, a través de los cuales se puede llegar a modificar la realidad procesal del litigio y conllevar a la culminación anómala de este.Ahora bien, dentro de las maneras de terminación no habitual del proceso en el recurso funcionarial, se pueden encontrar: La caducidad de la acción; el despacho saneador no cumplido; la cosa juzgada; la perención de la instancia; el decaimiento del interés procesal; y la incompetencia del tribunal, por mencionar algunas. 
La caducidad de la acción

Si bien, en materia de lo contencioso administrativo rige la Ley del Estatuto de la Función Pública, que consagra el procedimiento judicial aplicable a la recurso funcionarial. No obstante, de forma subsidiaria se aplican algunas disposiciones de la norma general establecida en la [24] Ley Orgánica de la Jurisdicción Contencioso Administrativa, al establecer que todo recurso con apoyo en la Ley sólo podrá ser ejercido válidamente dentro de un lapso de tres meses contado a partir del día en que se produjo el hecho que dio lugar a él, o desde el día en que el interesado fue notificado del acto.

Asimismo [25] consagra: la caducidad donde explana que las leyes especiales podrán constituir otros lapsos de caducidad y la demanda se declarará inadmisible si existe caducidad en la acción.

Entonces, [21] indica que de acuerdo a la normativa que rige la materia funcionarial; esto es, la especial, la Ley del Estatuto de la Función Pública y la general, la Ley Orgánica de la Jurisdicción Contencioso Administrativa; consagran la figura jurídica denominada caducidad de la acción, concebida como una limitante al ejercicio de la recurso funcionarial. [5]En otras palabras, la caducidad implica un tiempo en el cual se debe ejercer el derecho de acceso a la jurisdicción en el ámbito contencioso administrativo funcionarial; o sea, la caducidad presupone la existencia de un plazo legalmente previsto para el ejercicio de la acción jurisdiccional, y no admite interrupción o suspensión.

Aunado a lo anterior, se tiene que, para el caso de materializarse la caducidad de la acción, esa circunstancia implicaría la inadmisibilidad del recurso funcionarial; bien sea, decretado de oficio por el Juez, o bien sea, a petición de la contraparte o parte contraria en el litigio.
Del criterio [25], se infiere que, la caducidad de la acción se encuentra establecida en la materia contencioso administrativo funcionarial, cuyo lapso está dispuesto en la Ley del Estatuto de la Función Pública y de confirmarse tal figura jurídica se subsume en una causal para la inadmisibilidad de la recurso funcionarial. También enseña la jurisprudencia trascrita que, el lapso para la interposición de la recurso funcionarial (3 meses) comienza desde el día en que se produjo el hecho, la acción, o la omisión por parte del Estado Venezolano en cualquier de sus niveles del Poder Público; o desde la fecha en que se produjo la notificación del funcionario de tal hecho o acción emanada de la Administración Pública.

No obstante, el Máximo Tribunal de la República igualmente estableció que, si la notificación del funcionario de la manifestación de voluntad del Poder Público, no contiene la indicación relativa a: Los recursos que proceden contra la resolución de la Administración Pública-sean éstos administrativos o judiciales-; los términos para ejercerlos; y los órganos o tribunales ante los cuales se deben interponer. Si habiéndolos expresado la notificación, dichas indicaciones son erróneas; no transcurre el lapso de caducidad de la acción, esto, por considerarse a dicha notificación como defectuosa.

El despacho saneador no cumplido

[24] acuerda que, el despacho saneador tiene como finalidad hacer corregir o subsanar los recursos funcionariales ambiguas, oscuras o ininteligibles. Y, para el caso de la no materialización del despacho saneador, la inadmisibilidad de la demanda cuando se compruebe el transcurso del lapso permitido al actor a través del despacho saneador sin que aquel subsane el error en que hubiere incurrido o no presente la documentación o información solicitada por el órgano jurisdiccional a los fines de la admisión de la demanda; entonces, el incumplimiento de lo requerido mediante el 
despacho saneador trae como consecuencia, la inadmisibilidad de la recurso funcionarial.

\section{La Cosa Juzgada}

Otra de las formas de culminación no habitual del proceso según [21] en el recurso funcionarial, es la cosa juzgada, la cual ha sido presentada como la decisión contenida en la sentencia del juez cuando se ha tornado inmutable como consecuencia de la preclusión de las; por ello se argumenta que, la cosa juzgada implica la prohibición a los sujetos procesales del ejercicio de una nueva acción sobre lo ya decidido en una causa previa; o lo que es lo mismo, la imposibilidad del juez para volver a decidir un caso o asunto que fue resuelto en otro litigio anterior y donde existe identidad de los sujetos procesales, del objeto y del título. La cosa juzgada se presenta en dos (2) formas: La formal y la material.

La cosa juzgada formal, según [24], surge cuando no es posible interponer contra la sentencia el recurso de impugnación; bien porque la ley no lo prevé, o bien porque no se interpuso en el lapso dispuesto para ello. Y, la cosa juzgada material, acontece cuando la sentencia emitida es revisada por un juzgado de alzada, cuya determinación contiene el derecho que debe regir entre las partes. Una vez comprobada la materialización de la cosa juzgada, el tribunal acodará la inadmisibilidad de la acción.

\section{La perención de la instancia}

A pesar de que la legislación especial de la jurisdicción contencioso administrativa funcionarial, esto es, la [25], no establece normativa alguna sobre la perención de la instancia. No obstante, en la legislación general de la materia contencioso administrativa, [27], expone que, la perención de la instancia tiene cabida por la inactividad procesal, esto es, cuando la parte interesada, no realiza los actos procesales respectivos para el impulso de la causa o del litigio. En el ámbito de lo contencioso administrativo funcionarial, la perención se materializa, si a partir de la admisión de la recurso funcionarial transcurre más de un (1) año, sin que la parte interesada haya impulsado lo concerniente a la citación y a las notificaciones acordadas en el auto de admisión.

\section{El decaimiento del interés procesal}

Así lo conceptualiza [18], en este sentido, el interés procesal implica la necesidad que tiene una personal -sea natural o jurídica de acudir a los órganos jurisdiccionales, con el fin de solicitar el reconocimiento de un derecho ante otro sujeto procesal, o para reclamar un derecho menoscabado o afectado por una contraparte o adversario procesal.

Así pues, la pérdida del interés procesal surge por la inactividad procesal, al igual que la perención de la instancia. No obstante, aun cuando esas dos (2) figuras jurídicas se originan por la pasividad o apatía en el litigio, donde la parte interesada resulta ser el accionante, el Tribunal (Ley Orgánica de la Jurisdicción Contencioso Administrativa. , 2010) (Ley del Estatuto de la Función Pública, 2002) Supremo de Justicia determinó en el ámbito contencioso administrativo, los momentos en que se materializa la pérdida del interés procesal, así como el tiempo sobre el cual debe suponerse el acaecimiento de tal ficción jurídica, esto es, más de un (1) año de inactividad procesal.

Es menester indicar que, la pérdida del interés procesal se infiere luego de haber transcurrido más de un (1) año: Desde la fecha del recibido de la acción, demanda o recurso y antes de la fecha del pronunciamiento sobre la admisibilidad de la acción. $Y$, desde la fecha en que el tribunal dice 'vistos' y comienza el lapso para decidir la causa. Tiempo que debe transcurrir sin que conste en el expediente 
alguna actuación procesal cuyo fin sea el de impulsar el pleito judicial.

A pesar de lo anteriormente expuesto, y en el caso de que el juez presuma la pérdida del interés procesal, la ley le concede al accionante una nueva oportunidad para que manifieste el interés en continuar con la causa procesal.

\section{La incompetencia del tribunal}

Antes de discernir sobre la incompetencia del tribunal en materia de lo contencioso administrativo funcionarial, [22] establece que es requerido hacer alusión sobre los presupuestos procesales, los cuales han sido explicados por la Sala de Casación Civil, en el fallo publicado el 11/10/2000, expediente $N^{\circ}$ 99-191, sentencia $N^{\circ} 333$; se destaca que, el acceso a los órganos jurisdiccionales se efectúa mediante un libelo de demanda, escrito en el cual el juez debe verificar antes del pronunciamiento sobre la admisibilidad de la acción, determinadas exigencias que previó el Legislador. Dichos requerimientos van a estar ligados con la conducción del proceso, pues satisfechos éstos harán posible la facultad del juez para conocer de un litigio y para ejercer la función jurisdiccional, o sea, para resolver la controversia propuesta.

Entonces, comprobado de oficio por el juez los presupuestos procesales, se depurará el proceso de cualquier vicio que afecte la validez de la relación procesal.

$Y$, en el caso de que se haya admitido la acción, demanda o recurso sin el cumplimiento de cualquier de los presupuestos procesales, esto no obsta para que el juez en cualquier estado y grado de la causa, verifique la satisfacción de tales presupuestos, y ante el incumplimiento de alguno de ellos conllevará a la consecuencia jurídica correspondiente, o sea, la inadmisibilidad de la acción.
Incompetencia por la materia

Efectuado el discernimiento sobre los presupuestos procesales, [4] infiere que se encuentra incluida, la competencia del juez ante el cual corresponda el conocimiento del asunto; es menester hacer alusión sobre la competencia de los tribunales contenciosos administrativos en el área funcionarial.

Para aseverar que, la competencia de los tribunales contenciosos administrativos funcionariales viene dada por la naturaleza de la pretensión; por lo que, toda controversia que se derive con motivo de los actos, los hechos, o las omisiones que provengan de los órganos y entes del Poder Público, debe gestionarse mediante el recurso funcionarial, la cual será tramitada y decidida por el Juez natural, es decir, por los Jueces que encabezan los Juzgados Superiores Estadales de la Jurisdicción Contencioso Administrativa.

Entonces, sólo los funcionarios de carrera y los funcionarios de libre nombramiento y remoción, ante cualquier comportamiento -acción u omisión- del Estado Venezolano en cualquiera de sus órganos del Poder Público, que implique el detrimento de los derechos y de los beneficios derivados de la relación de empleo público; tienen la potestad de ejercer la acción en materia contencioso-administrativa funcionarial, la cual ha sido denominada como: El Recurso Contencioso Administrativo Funcionarial, el recurso funcionarial.

\section{Conclusiones}

De acuerdo con el ordenamiento jurídico venezolano, la persona que amerite activar a los órganos jurisdiccionales para hacer valer sus derechos o para el restablecimiento de la situación jurídica subjetiva que le ha sido infringida, debe poseer cualidad; es decir, ser titular del interés jurídico que se constituye en la necesidad que tiene una persona, derivada por alguna circunstancia o situación, que hace 


\section{0}

meritorio de que acuda a la vía judicial para que se le reconozca un derecho, para hacerlo valer, para que se le evite un daño, o para que la lesión o desmedro ocasionado no continúe. Esa necesidad de impulsar los tribunales, está obligada dentro de los elementos pretendidos para la validez del proceso. La cualidad, ha sido establecida como el vínculo jurídico innato entre la persona que asevera tener un interés jurídico propio para pretender una reclamación en vía jurisdiccional y el sujeto procesal a quien la ley le concede la potestad para proponer -cualidad activa- o para soportar - cualidad pasiva- la acción judicial.

El Recurso Contencioso- Administrativo Funcionarial, es el medio judicial eficiente con el que cuentan los funcionarios para reclamar los derechos y los beneficios derivados del empleo público. Acción a través de la cual se proyecta cualquier polémica que se suscite con motivo de la reclamación de los funcionarios, cuando éstos crean que ante la acción $u$ omisión por parte de la Administración Pública; esta implique el menoscabo, de los derechos y de los beneficios laborales.

Por otro lado, en lo que atañe a las maneras extrañas que terminan el proceso en los recursos funcionariales, se encontró que, cuando se activa la vía jurisdiccional, el trámite de esa acción, demanda, recurso, amparo, o reclamo, debe gestionarse mediante las fases, los actos y los lapsos previamente establecidos por la Ley, y cuyo acto procesal final es la sentencia.

No obstante, concurren situaciones que acarrean que la decisión del Juez no implica el que realiza un examen de la pretensión, sino que ésta sufre la terminación anormal del proceso, caída no habitual del proceso o modos excepcionales que ponen término a la relación procesal.
Referencias

[1] M. De La Cueva, La ideas del Estado, Mexico, 2014

[2] M. Laporte, "El principio de probidad y publicidad de los actos de la administración", Revista universitaria, 2016

[3] L. Traversi, Órganos y Agentes Estatales, Valencia-Venezuela, 2012

[4] L. Useche, "El Sistema Político y Constitucional del Estado Contemporáneo", Revista Tachirense de Derecho, 2002

[5] A. Brewer, Derecho Administrativo. Tomo II. (1ra ed.), Caracas: Editorial Jurídica Venezolana, 2006

[6] F. Arias, El Proyecto de Investigación. Introducción a la Metodología Científica, Caracas: Episteme C.A, 2006

[7] E. Arbeloa, El derecho a una buena administración Responsabilidad de los cargos públicos, España, 2013

[8] M. Javato, "El Concepto de Funcionario y Autoridad a Efectos", Revista Juridica de Castilla y León, 2011

[9] O. White, Evolución del Derecho Administrativo y su teoría General en el proceso, 2008

[10] D. Urosa, Origen y Evolución del Contencioso Administrativo. Caracas, 2009

[11] A. Aldaz, El Juicio Ordinario de Mayor Cuantía: Celeridad y economia procesal, UNIANDES, 2015

[12] J. González, "La Terminación Anormal del Proceso Administrativo", Revista Juridica de la Universidad de Mexico, 2016 
[13] L. Alvarado, "Reflexiones Teóricas: Valores Éticos en la Prestación de servicios de la administracion pública", Revista de UCLA, 2011

[14] C. Carrillo, Ámbito subjetivo del derecho disciplinario público en Venezuela, Caracas: Forum, 2011

[15] J.H.M. López "Los Contratados en la administracion pública", Revista de la Universidad del Zulia, vol. 8, 2014

16] R. Pernía, "Procedimiento de determinación de responsabilidad de los funcionarios públicos", Revista de Derecho UCAT, 2016

[17] M. Rivera, "El acto administrativo electrónico en Venezuela", Revista UCAT, vol. 32, 2015

[18] J. Alegría, "La Terminación Anticipada en el Proceso Administrativo", Revista de Universidad de San Martín de Porres (USMP), 2014

[19] J. Araujo, Tratado de Derecho Administrativo Formal, Caracas: Vadell Hermanos, 2012

[20] L. Molina, "La asistencia jurídica en el marco de los procedimientos administrativos sancionatorios", Revista Tachirense de Derecho, 2015

[21] C. Quintana, Formas de Terminación del Proceso Contencioso- Administrativo, Valencia. Fides, 2011

[22] Constitución de la República Bolivariana de Venezuela. Caracas: Vadell Hermanos, 2009

[23] Ley Orgánica de la Jurisdicción Contencioso Administrativa. Valencia: Vadell Hermanos, 2010

[24] Ley del Estatuto de la Función Pública. . Caracas: Dabosan, 2002 